Aplicação de Extrato de Própolis em Produtos Alimentícios: Uma Prospecção Baseada em Documentos de Patentes

Silva, R. P. D.;* Machado, B. A. S.; Costa, S. S.; Barreto, G. A.; Padilha, F. F.; Umsza-Guez, M. A.

Rev. Virtual Quim., 2016, 8 (5), 1251-1261. Data de publicação na Web: 4 de julho de 2016

http://rvq.sbq.org.br

\title{
Application of Propolis Extract in Food Products: A Prospecting Based in Patent Documents
}

Abstract: Due to the characteristics of propolis, their extracts have been used in various products; the process has its technology developed and it is protected by patent documents. The aim of the study was to perform a technological forecasting of the application of propolis extracts in food products. The search was conducted in the online base of Espacenet and INPI. The results showed that Japan stands out as the largest holder of the corresponding technology although importing almost the totality of propolis from Brazil. Brazil, despite being the third country in the world producing propolis, does not have a domain protection of this technology.

Keywords: Propolis; food; industrial property; patents; technology prospecting.

\section{Resumo}

Devido às características da própolis, seus extratos têm sido utilizados em diversos produtos, que tem sua tecnologia desenvolvida e protegida por documentos de patentes. O objetivo do estudo foi realizar uma prospecção tecnológica sobre a aplicação de extratos de própolis em produtos alimentícios. A busca foi realizada na base online do Espacenet e do INPI. Os resultados demonstraram que o Japão destacase como o maior detentor da tecnologia pesquisada apesar de importar quase a totalidade do produto do Brasil. O Brasil mesmo estando em terceiro lugar na produção mundial de própolis, não possui ainda um domínio de proteção dessa tecnologia.

Palavras-chave: Própolis; alimentos; propriedade industrial; patentes; prospecção tecnológica.

* Universidade Federal da Bahia, Faculdade de Farmácia, Programa de Pós-graduação em Ciência de Alimentos, Campus Universitário de Ondina, CEP 40170-290, Salvador-BA, Brasil.

Mrepinna@yahoo.com.br

DOI: $\underline{10.21577 / 1984-6835.20160090}$ 


\title{
Aplicação de Extrato de Própolis em Produtos Alimentícios: Uma Prospecção Baseada em Documentos de Patentes
}

\author{
Rejane P. D. Silva, ${ }^{a, b}$ Bruna Aparecida S. Machado, ${ }^{b, c}$ Samantha S. Costa, ${ }^{b}$ \\ Gabriele A. Barreto, ${ }^{b}$ Francine F. Padilha, ${ }^{c}$ Marcelo Andrés Umsza-Guez ${ }^{a}$ \\ ${ }^{a}$ Universidade Federal da Bahia, Faculdade de Farmácia, Programa de Pós-graduação em \\ Ciência de Alimentos, Campus Universitário de Ondina, CEP 40170-290, Salvador-BA, Brasil. \\ ${ }^{\mathrm{b}}$ Faculdade de Tecnologia SENAI CIMATEC (Serviço Nacional de Aprendizagem Industrial), \\ Avenida Orlando Gomes, 1845, Piatã, CEP 41650-010, Salvador-BA, Brasil.
}

${ }^{c}$ Universidade Tiradentes, Avenida Murilo Dantas, 300, Farolândia, CEP 49032-971, Aracaju-SE, Brasil.

* repinna@yahoo.com.br

Recebido em 18 de maio de 2015. Aceito para publicação em 4 de julho de 2016

\section{Introdução}

\section{Metodologia}

2.1. Estratégia de Busca

2.2. Escopo

\section{Resultados e Discussão}

4. Conclusão

\section{Introdução}

A própolis é uma substância resinosa ou algumas vezes cerosa, coletada por abelhas melíferas de diferentes exsudatos vegetais. Tem sido utilizada na medicina tradicional desde a antiguidade devido ao seu largo espectro de atividade biológica como antioxidante, antinflamatório, antibacteriano, antiviral, antifúngico e, até mesmo, anticancerígeno. ${ }^{1} \mathrm{O}$ uso de extratos de própolis na medicina popular data de 300 a.C. ${ }^{2}$. O Brasil é um dos principais produtores mundiais de própolis, com uma produção estimada em torno de 50 a 150 toneladas por ano, sendo que cerca de $75 \%$ desse total é exportado, especialmente para o Japão (97 \% das exportações) $)^{3}$, o que significa $80 \%$ da demanda japonesa. ${ }^{4} \mathrm{O}$ aumento do interesse pelo extrato de própolis brasileira, inserido no contexto do comércio internacional de alimentos, tem gerado como consequência o aumento do valor agregado do produto. ${ }^{5}$ Dados da Federação de Apicultores de Minas Gerais revelam que a própolis produzida no Estado é considerada a melhor do mundo no mercado japonês, onde o quilograma do produto saltou de US\$ 5 para US\$ 200 nos últimos anos. Todas essas características panaceias e agregado ao fato de a própolis possuir um alto valor agregado justificam o 
grande interesse global de pesquisas envolvendo a própolis. ${ }^{4}$

Pelo menos 200 componentes diferentes já foram identificados em amostras de própolis de origens diversas, dentre esses, ácidos graxos e fenólicos, ésteres, ésteres fenólicos, flavonoides (flavonas, flavanonas, flavonóis, di-hidroflavonóis), terpenos, besteroides, aldeídos e álcoois aromáticos, sesquiterpenos e naftaleno ${ }^{1-6}$. De acordo com Paulino, ${ }^{7}$ o sabor, a cor, o odor, a consistência, a composição química e a atividade biológica da própolis dependem diretamente das espécies vegetais que the deram origem e da época do ano em que foram produzidas. Consequentemente essa composição complexa não pode ser definida de uma maneira geral e dificulta a padronização da própolis para comercialização, uma vez que, por exemplo, a variação sazonal pode diminuir ou aumentar diferentes componentes biologicamente ativos da própolis. ${ }^{8}$ Porém, essa também é a principal justificativa para a grande diversidade e quantidade de estudos com diferentes amostras desse material. ${ }^{9}$

Devido as suas importantes características, a própolis é cada dia mais usada em aplicações industriais que facilitam o acesso à população. Ao longo dos anos os extratos de própolis têm sido utilizados em alimentos e produtos alimentícios, preservação de diversos produtos, cosméticos e produtos de higiene, produtos fármacos, e principalmente preparações para finalidades médicas e odontológicas como pode ser evidenciado em diferentes estudos prospectivos envolvendo a própolis. Pereira et $\mathrm{al}^{4}{ }^{4}$ avaliou os avanços dos estudos envolvendo a matriz própolis com base no número de trabalhos publicados e pedido de patentes, onde percebeu que há um crescimento quase exponencial do número total de publicações bem como nos depósitos de patentes. Da mesma forma Lutosa et $\mathrm{al}^{10}$ evidenciou que de 2003 até o início de 2008 houve um maior aprofundamento nos estudos relativos a própolis com um exponencial interesse pela matriz, sua composição química e atividade biológica.
Recentemente, Machado et al, ${ }^{11}$ realizaram um estudo prospectivo da própolis $\mathrm{e}$ tecnologias correlatadas no cenário brasileiro e identificaram o panorama nacional da proteção de processos e produtos relacionados a essa matriz, relacionando os documentos de patentes depositados no Brasil.

De acordo com o Codex Alimentarius, ${ }^{12}$ alimento é qualquer substância, tanto processada, semi-processada ou crua, utilizada na intenção de consumo humano, incluindo bebidas, gomas de mascar e qualquer substância que seja usada em manufatura, preparação ou tratamento de alimentos. Cada vez mais pesquisas sobre a aplicação de própolis em alimentos se destacam e tendem a se tornarem frequentes frente ao amplo cenário de propriedades biológicas que este produto apresenta. ${ }^{13-14}$

Com isso, o objetivo do estudo foi realizar uma prospecção tecnológica baseada em documentos de patentes depositados no mundo sobre a aplicação de extrato de própolis em produtos alimentícios. A prospecção foi realizada utilizando a ferramenta de busca de anterioridade, através da qual é possível avaliar se a tecnologia em questão já foi desenvolvida e apropriada, realizar um levantamento de todas as tecnologias existentes, identificar as tecnologias concorrentes e lacunas a serem preenchidas. Além disso, é possível identificar os inventores, os países de origem dos depósitos, as principais empresas depositantes e a classificação dos depositantes. ${ }^{15}$

\section{Metodologia}

\subsection{Estratégia de Busca}

A busca foi realizada na base online do Escritório Europeu de Patentes (Espacenet), uma base de acesso livre para prospecção e buscas de anterioridade, e que, compila mais 
de oitenta milhões de documentos de patentes depositados em mais de 90 países, e na base de dados online do escritório nacional, Instituto Nacional de Propriedade Industrial (INPI), que compila o acervo de patentes depositadas no Brasil. A metodologia adotada para a busca da tecnologia descrita em documentos de patentes (Figura 1) foi à combinação do campo da Classificação Internacional de Patentes (IPC) que especifica a categoria que - assunto de interesse está classificado, associado a uma combinação de palavraschave contidas no título ou resumo do documento protegido para identificação da matriz estudada. Neste caso o ICP foi limitado a utilização dessa tecnologia em alimentos, inseridos nas classificações: A23B, A23C, A23D, A23F, A23G, A23J, A23K e A23L; associados a palavras-chave (propolis, propolis extract, extrato, produto, bebida, alimento).

Através do editor CSVed.exe foi possível exportar e extrair os dados para uma planilha do Microsoft Excel e analisa-las conforme sua data de depósito e de publicação, tipo de depositante, país de origem, inventores e classificação do documento. Em seguida, os dados extraídos foram tratados, analisados e representados em gráficos que apresentam as informações referentes à tecnologia patenteada, ou seja, a aplicação do extrato de própolis em produtos alimentícios, depositadas em todo o mundo. A Figura 1 apresenta um fluxograma dos passos utilizados para desenvolvimento da prospecção tecnológica.

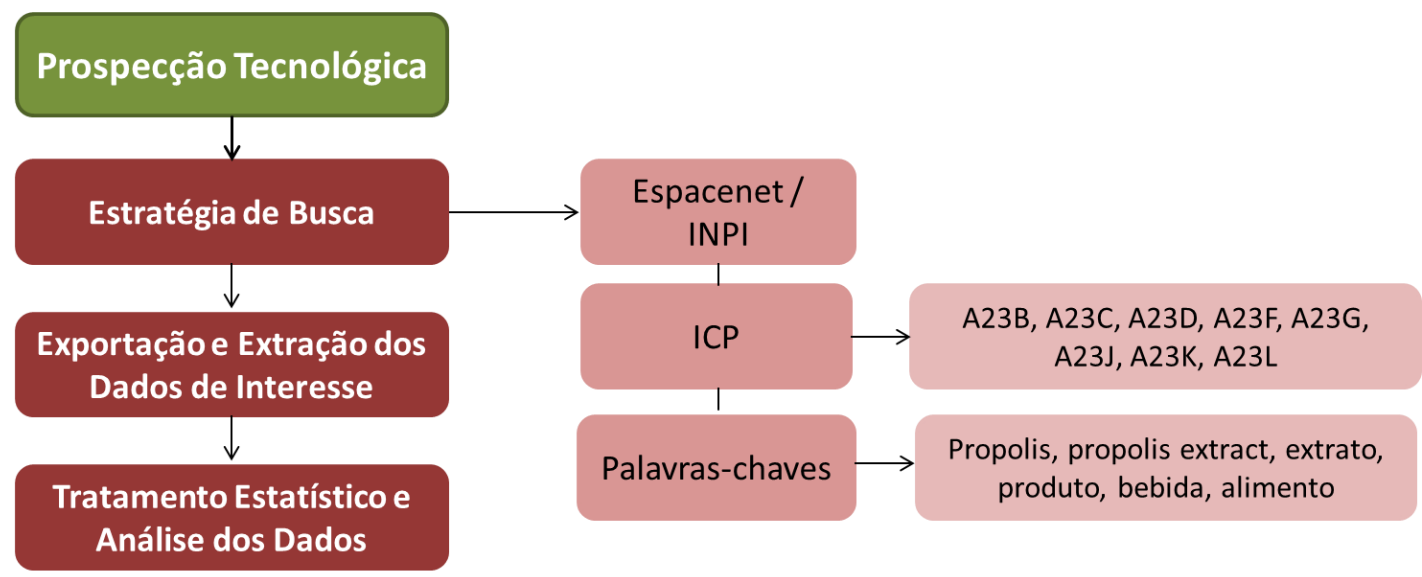

Figura 1. Fluxograma de Prospecção Tecnológica

\subsection{Escopo}

A pesquisa realizada na base de dados do Escritório Europeu de Patentes com a palavra-chave geral (própolis) resultou em um universo de registros de mais de 2.700 documentos. Ao combinar a palavra-chave com diferentes códigos de classificação definidos previamente (Tabelas 1 e 2) foi possível reduzir a quantidade de documentos identificados refinando a pesquisa de interesse. Após análise dos dados através das diferentes combinações de códigos com a palavra-chave própolis, identificou-se que a melhor pesquisa era representada pela associação do código A23L com as palavraschave propolis and extract, que resultou em uma identificação de 358 documentos de patentes referentes à tecnologia estudada no Espacenet Worldwide database (Tabela 2).

Após uma análise detalhada dos resumos dos documentos identificados foram selecionados um total de 257 documentos das bases de dados os quais estavam diretamente relacionados com a tecnologia em questão, bem como, excluídos os documentos semelhantes identificados nas 
duas bases. Destes documentos foram extraídas as informações que deram origem aos dados apresentados e discutidos neste trabalho.

$\mathrm{Na}$ Tabela 1 são demonstrados os resultados obtidos após a busca na base de dados do Instituto Nacional de Propriedade Industrial (INPI) e a Tabela 2 apresenta o levantamento realizado na base de dados Europeia (Espacenet) para os códigos de classificação internacional que abrangem a tecnologia estudada. Assim, foi possível constatar que o maior número de patentes depositadas envolvendo a utilização do extrato de própolis, possui maior concentração na classificação $\mathrm{A} 23 \mathrm{~L}$ que descreve Alimentos, produtos alimentícios, bebida não alcoólicas, não abrangidas pela subclasse $A 23 B$ a A23J; seus métodos de preparo; preservação de alimentos em geral.

Tabela 1. Palavras-chave em bancos de dados INPI

\begin{tabular}{|c|c|c|c|c|c|}
\hline Própolis & Extrato & Produto & Bebida & Alimento & INPI \\
\hline$x$ & & & & & 104 \\
\hline$x$ & $x$ & & & & 49 \\
\hline$x$ & & $x$ & & & 31 \\
\hline$x$ & & & $x$ & & 5 \\
\hline$x$ & & & & $x$ & 2 \\
\hline
\end{tabular}

Tabela 2. Total de documentos obtidos por busca no Espacenet Worldwide database propolis and extract* A23B A23C A23D A23F A23G A23J A23K A23L A23P EP

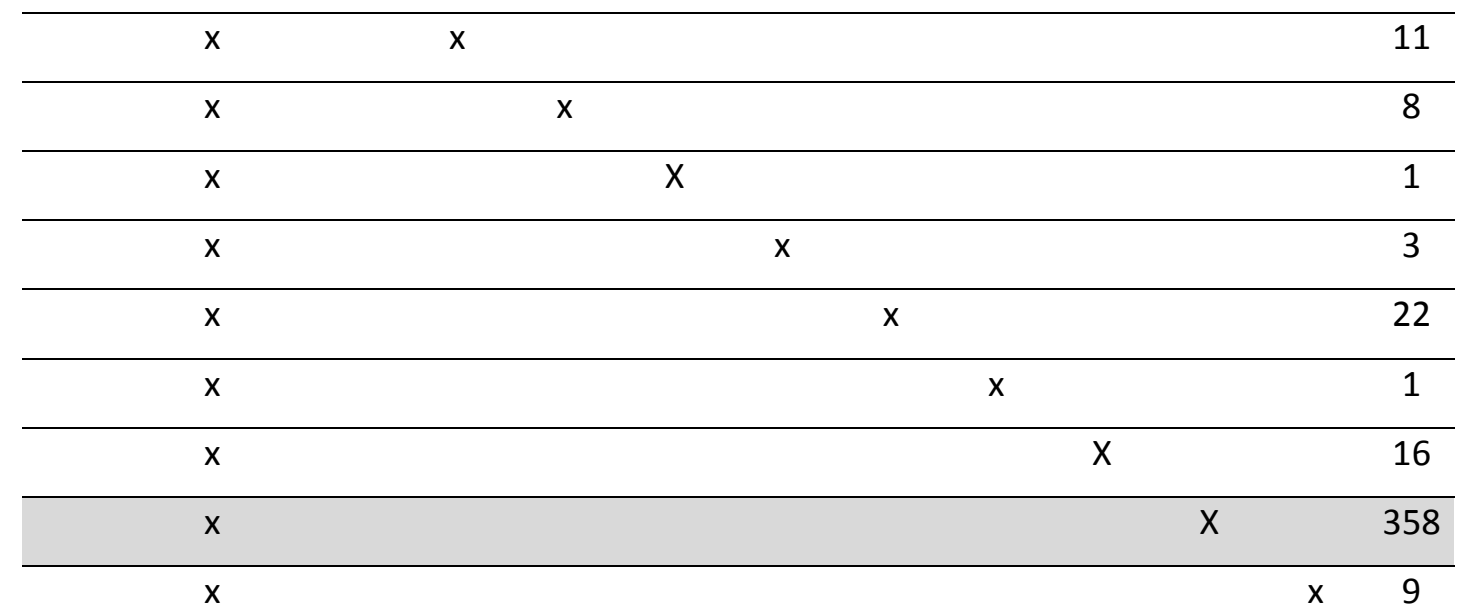

A23B: Preservação, carne, peixe, ovos, frutas, legumes, sementes comestíveis; amadurecimento químico de frutas ou legumes; Produtos preservados, amadurecidos, ou enlatados; A23C: Produtos lácteos, por exemplo Leite, manteiga, queijos; Substitutos do leite ou queijo; Método de preparação; A23D: Óleo alimentares, por exemplo margarinas, gorduras, óleos de cozinha; A23F: Café, chá; Seus substitutos; Fabricação, preparação, ou infusão da mesma; A23G: Cacau; Produtos derivados do cacau, por exemplo, chocolate; Substitutos para cacau ou produtos de cacau; confeitaria; Goma de mascar; Sorvete; Método de preparação; A23J: composições de proteínas para o gênero alimentício; Composição de Fosfatidio; A23K: Forragem; A23L: alimentos; produtos alimentícios, ou não alcoólicos, não abrangidos pela subclasse A23B a A23J; Método de preparação ou tratamento; conservação dos alimentos ou gêneros alimentícios em geral; A23P: Molde ou trabalho de produto alimentício não totalmente cobertos por uma outra subclasse. 


\section{Resultados e Discussão}

A evolução anual do depósito de patentes encontra-se representada na Figura 2. A primeira patente depositada foi em 1982 e se trata de um tônico com propriedades antibióticas, antibacterianas e viricida para ser utilizado na medicina humana $e$ veterinária e se caracteriza pela composição de extrato de própolis, xarope de açúcar de beterraba, água e aromas. A patente foi depositada por Peter Glienk na Alemanha.

Desde então a produção de depósitos de patentes sobre a utilização extrato de própolis aplicado a produtos alimentícios se manteve baixa até o início dos anos 90. A partir de 1997 houve um crescimento acentuado dos depósitos de patentes.

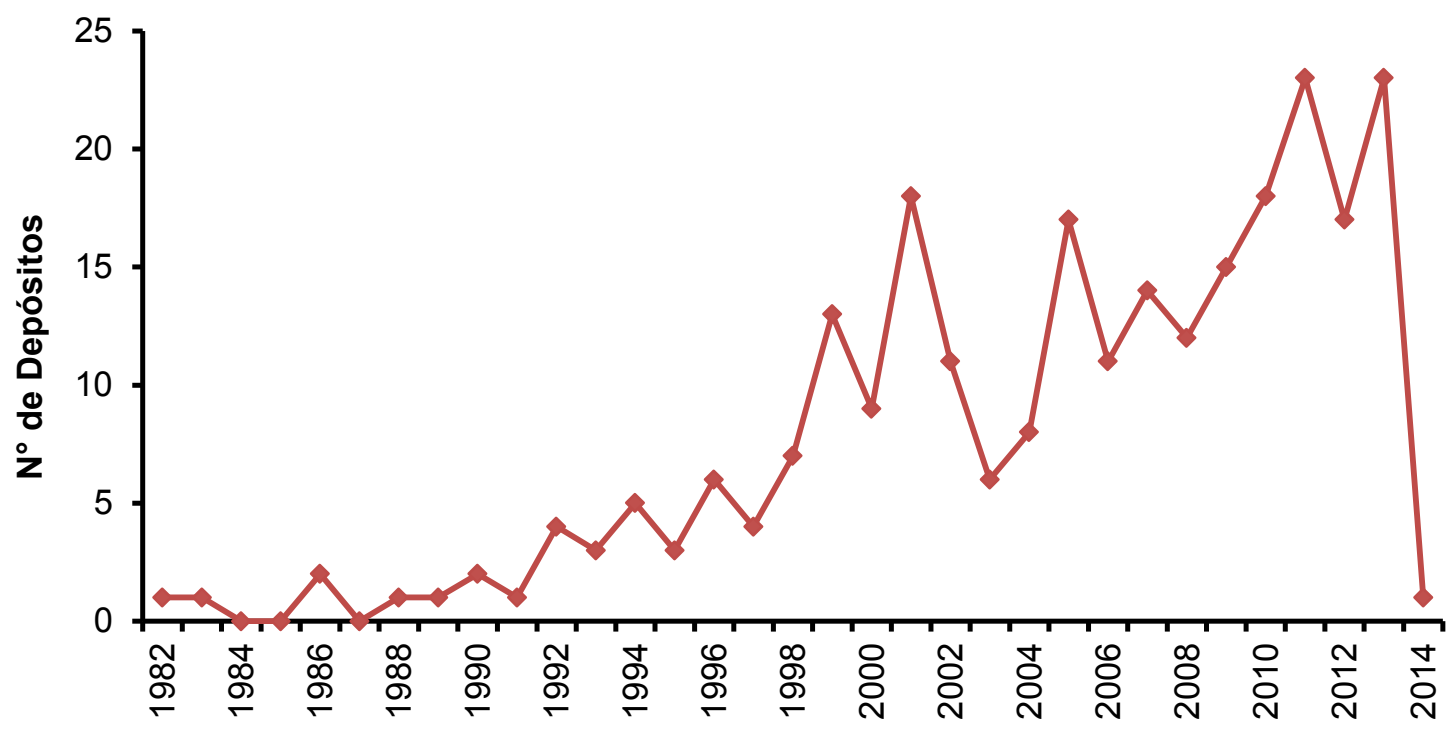

Ano de Depósito

Figura 2. Evolução anual do depósito de patentes relacionadas ao uso de própolis em produtos alimentícios (1982 - 2014)

Nas décadas de 80 e 90 os principais países do mundo em número de publicações (Rússia, Japão, Itália, Bulgária e Polônia) tiveram um crescimento substancial em números de publicações sobre própolis. 0 Japão em especial apresentou um aumento de $660 \%$ nas suas publicações. ${ }^{4}$ Consequentemente esse maior aprofundamento nos estudos relativos a própolis refletiu no crescimento de depósitos de patentes a partir dos anos 90, com destaque para o ano de 1999 que registrou o depósito de 13 patentes associadas a tecnologia pesquisada. Vale ressaltar que anteriormente a esta década, o depósito de patentes já era observado, porém com base nas propriedades farmacológicas do extrato de própolis, principalmente relacionadas com sua atividade antimicrobiana. ${ }^{4}$

A partir de 2008 nota-se um crescimento mais estável dos depósitos de patentes na tecnologia estudada. Esta tendência pode estar relacionada ao crescimento do mercado de produtos naturais nos últimos 6 anos, observando-se uma aumento acima de $20 \%$ por ano. ${ }^{16-17}$

Com a procura e o consumo de produtos naturais aumentados significativamente, 0 número de novos produtos inseridos no mercado também cresceu. Neste cenário o uso do extrato de própolis tem destaque por 
atribuir a um produto alimentício suas características antioxidantes, antimicrobianas, antifúngica e antiviral, substituindo as substâncias sintéticas comumente utilizadas. No ano de 2014 o total de invenções identificadas não representa o valor real, tendo em vista o período de sigilo proposto na legislação patentária, onde os documentos de patentes só são publicados após 18 meses da data do depósito.

Outra pesquisa realizada foi relativa aos principais países depositantes. Dentro do cenário apresentado, o Japão destaca-se como o maior detentor da tecnologia pesquisada. Conforme a Figura 3, o país possui um número de 78 patentes depositadas, o que representa $30 \%$ dos documentos de patente identificados. Em segundo e terceiro lugar aparecem a China e a Coréia do Sul com $26 \%$ e $25 \%$ dos depósitos, respectivamente. Estes dois países também são grandes pesquisadores na área da tecnologia em questão.

O Brasil juntamente com a Rússia e depósitos via o tratado de cooperação de patentes PCT (Patent Cooperation Treaty) não possui um número expressivo de depósitos, porém demonstram atividade em pesquisas com a aplicação de própolis em produtos com fins alimentícios. Os demais 8 países somados representam apenas $5 \%$ dos depósitos encontrados.

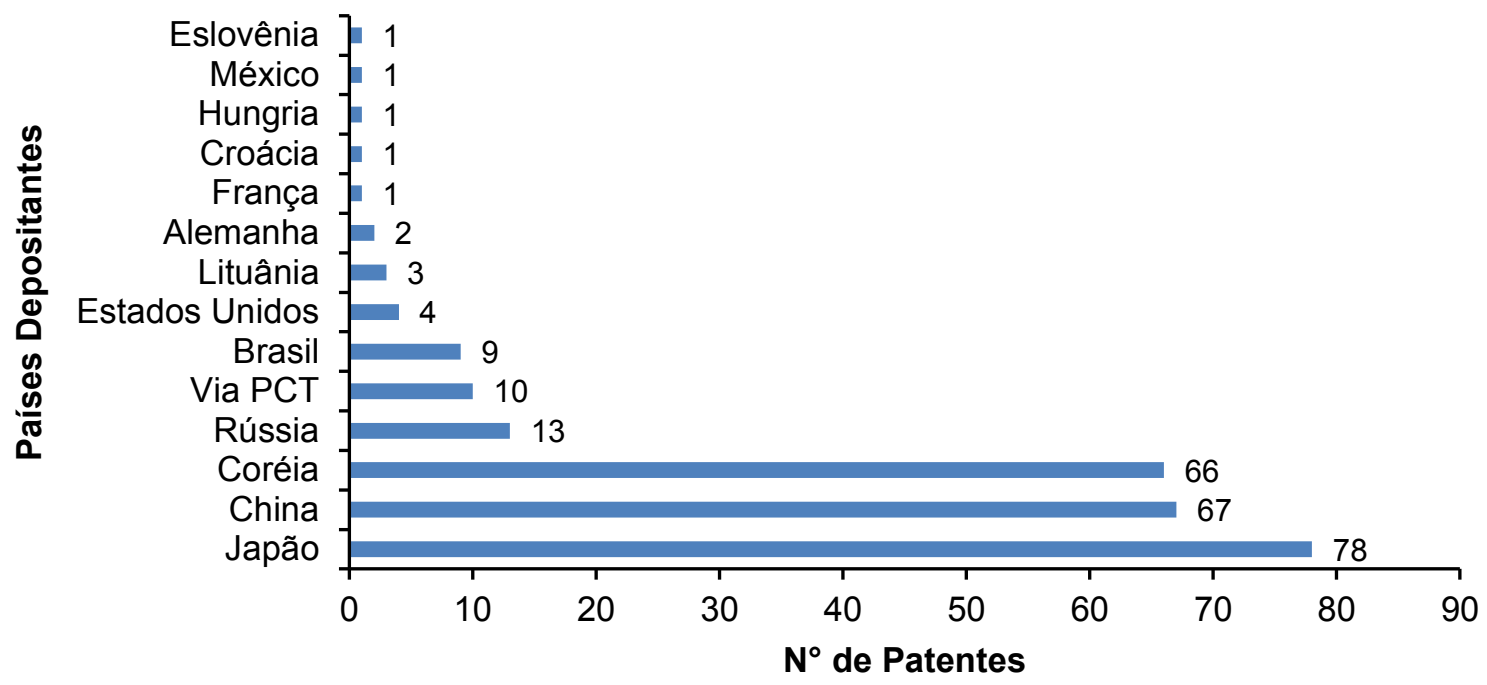

Figura 3. Distribuição dos depósitos de patentes por país de origem/região relacionados à utilização de própolis em produtos alimentícios (PCT: Patent Cooperation Treaty)

O Brasil é atualmente o terceiro maior produtor de própolis do mundo, perdendo apenas para a Rússia e a China e, embora produza de 10 a $15 \%$ da produção mundial, o Brasil atende a cerca de $80 \%$ da demanda de própolis do Japão. ${ }^{4}$

Machado et al., ${ }^{11}$ avaliaram o depósito de patentes relacionadas a própolis no Brasil em toda sua extensão de possibilidades de aplicações e observou que o país não é uma área de interesse para proteção revelado através do pequeno número de patentes de não residentes, o que reflete a falta de competitividade tecnológica e a necessidade de mais incentivos que visem aumentar o cenário inovativo do país.

Conforme apresentado na Figura 4, os países produziram suas patentes individualmente, sem associações entre si. Os depositantes que mais produziram foram as empresas japonesas multinacionais de pesquisa e desenvolvimento API $\mathrm{CO}$ e MORIKAWA KENKOUDOU KK, com 12 e 7 patentes depositadas respectivamente. A 
RYU HEE CHEOL da Coréia e a G NAUCHNOE UCHREZHDENIE NII russa depositaram 6 documentos de patentes cada. No Brasil, o Serviço Nacional de Aprendizagem Industrial (SENAI BA) em conjunto com a empresa Apis Jordans depositou 4 patentes referente a tecnologia estudada.
O Brasil possui apenas 9 patentes depositadas referente a utilização de extrato própolis aplicados a produtos alimentícios. Dados de depósitos de patentes indicam que o país possui principal interesse na área relacionada às propriedades médicas, odontológicas e higiênicas da própolis. ${ }^{11}$

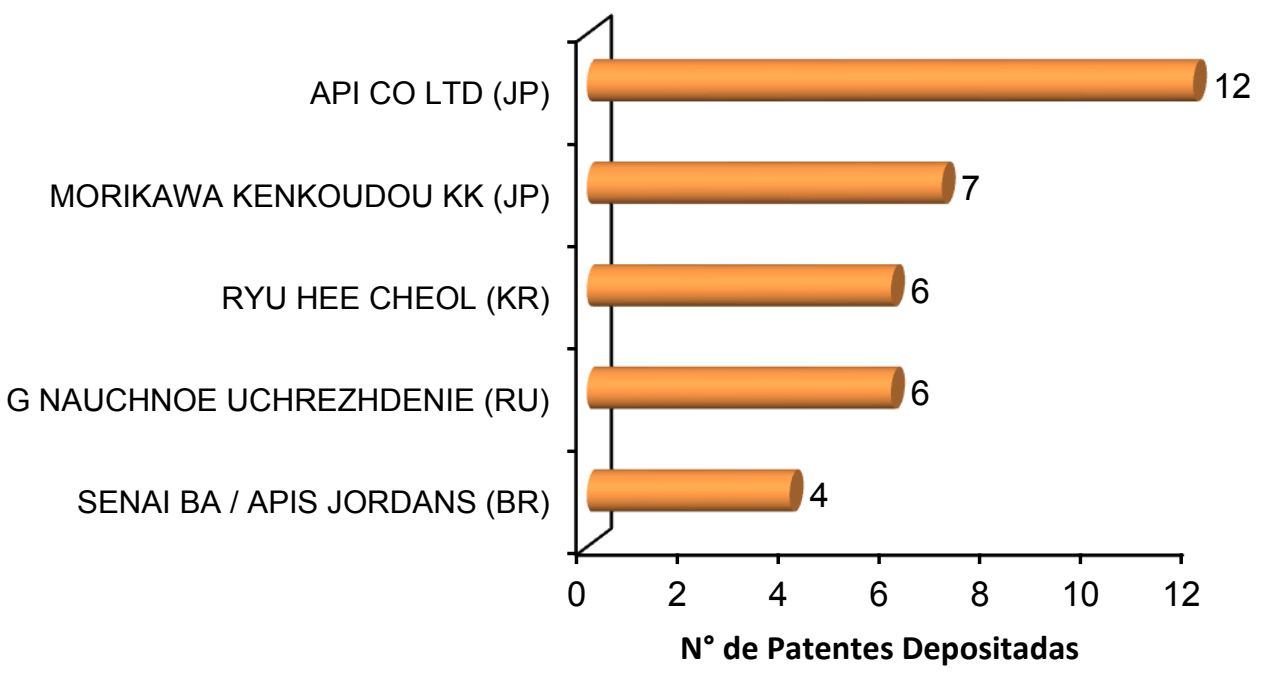

Figura 4. Maiores depositantes de patentes referentes à tecnologia estudada

As patentes envolvem a produção de bebida energética, água aromatizada $\mathrm{e}$ suplemento/complemento alimentar. A primeira patente foi depositada em 1999, e compreendeu a formulação de um suplemento alimentar apiterápico, composto por geleia real, pólen e própolis. Dentro da tecnologia em questão, o Estado da Bahia se destaca com o depósito de 6 patentes das 9 depositadas.

Dentro do código de classificação internacional analisado (A23L), percebe-se uma concentração de depósitos de patentes na subclasse A23L1, que contempla de modo geral os alimentos ou produtos alimentícios e suas preparações, representando 233 das patentes depositadas. Com uma porcentagem bem menor de incidência, 33 patentes depositadas, aparece a subclasse A23L2 que especifica a categoria das bebidas não alcoólicas, composições em pó ou concentradas e seus métodos de preparação. Por fim, aparece a categoria A23L3, com apenas 1 patente depositada. Esta última subclasse compreende produtos para preservação de alimentos ou produtos alimentícios em geral. A distribuição por incidência nas subclasses é apresentada na Figura 5.

Sendo assim, percebe-se que a grande maioria dos produtos alimentares adicionados de própolis existentes hoje no mercado tem o objetivo de conferir características benéficas à saúde, considerados como alimentos funcionais, como leite em pó, chá e bebidas fermentadas. Também são encontrados produtos que possuem a adição de própolis para prevenção da alteração da qualidade microbiológica dos mesmos, agindo como conservante do produto. 


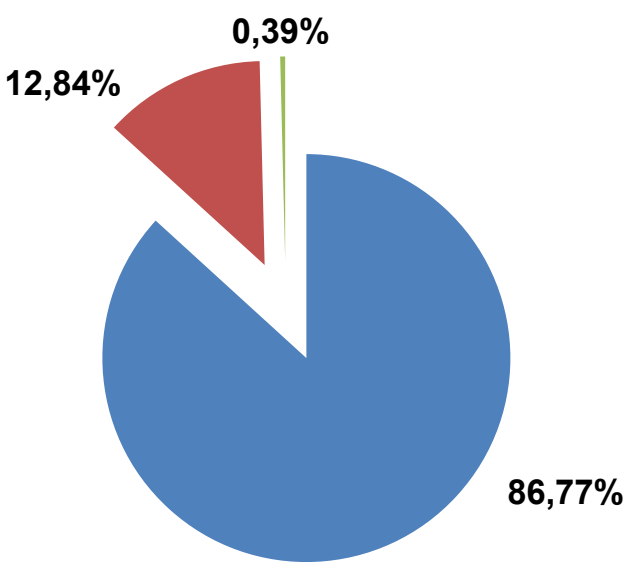

$\because$ A23L1 A23L2 $\because$ A23L3

Figura 5. Distribuição por incidência nas subclasses

As publicações referentes à aplicação de própolis em produtos para fins alimentícios têm avançado. Várias são as pesquisas recentemente relatadas nesta área, como por exemplo, estudos sobre a possibilidade de utilização de própolis como aditivo natural em sucos de maçã ${ }^{18}$ e utilização de própolis como preservação natural de filés frescos de peixes. ${ }^{19}$ Além disso novas áreas também tem sido exploradas para a aplicação de própolis, como na alimentação animal. Estudos relatam a aplicação da própolis em dietas de frangos, ${ }^{20}$ avaliação do efeito de produtos à base de própolis na produção de leite, na composição de ácidos do leite e na capacidade antioxidante do leite de vacas leiteiras em lactação média. ${ }^{21}$

Dessa forma, percebe-se que o campo de aplicação da própolis é bastante vasto, e que esse potencial vem sendo explorado cada dia mais.

\section{Conclusão}

A partir da busca de dados foi possível concluir que o Japão é o país detentor da aplicação da tecnologia estudada, apesar de o país importar a maior parte da matériaprima em questão, a própolis. O Brasil apesar de estar em terceiro lugar na produção mundial de própolis, não possui ainda um domínio de proteção dessa tecnologia, apresentando apenas um total de 9 depósitos dentro de um universo de 257 patentes depositadas no período estudado. Portanto, se faz necessário o entendimento por parte das indústrias, centros de pesquisas e desenvolvimento e academias de que o hábito de proteger suas atividades por meio do depósito de patentes é essencial para a competividade, notoriedade

desenvolvimento do país.

\section{Referências Bibliográficas}

${ }^{1}$ Marcucci, M. C.; Ferreres, F.; GarcíaViguera, C.; Bankova, V. S.; de Castro, S. L.; Dantas, A. P.; Valente, P. H. M.; Paulino, M. Phenolic compounds from Brazilian propolis with pharmacological activities. Journal of Ethnopharmacology 2001, 74, 105. [CrossRef] [PubMed]

${ }^{2}$ da Silva, J. F. M.; de Souza, M. C.; Matta, S. R.; de Andrade, M. R.; Vidal, F. V. N. Correlation analysis between phenolic levels of Brazilian propolis extracts and their antimicrobial and antioxidant activities. Food Chemistry 2006, 99, 431. [CrossRef] 
${ }^{3}$ Lima, G., Estudo sobre Mel, Cera e Própolis. Disponível em: $<$ http://gestaoportal.sebrae.com.br/setor/api cultura/acesse/biblioteca/estudo mel cera propolis.pdf>. Acesso em: 15 janeiro 2015.

${ }^{4}$ Pereira, A. S.; Seixas, F. R. M. S.; Neto, F. R. A. Própolis: 100 anos de pesquisa e suas perspectivas futuras. Química Nova 2002, 25, 321. [CrossRef]

${ }^{5}$ Sítio do Serviço Brasileiro de Apoio às Micro e Pequenas Empresas (SEBRAE). Disponível em:

<http://www.sebrae2014.com.br/Sebrae/Seb rae\%202014/2013 09 20 BO Agosto Agron egocio Propolis2.pdf> Acesso em: 4 Abril 2015.

${ }^{6}$ Aga, H.; Shibuta, T.; Sugimoto, T.; Kurimoto, M.; Nakajima, S. Isolation and identification of antimicrobial compounds in Brazilian propolis.Bioscience, Biotechnology, and Biochemistry 1994, 58, 945. [CrossRef]

7 Paulino, F. D. G. Em Produtos da Colmeia em Apicultura: manual do agente de desenvolvimento rural; Souza D. C., ed.; SEBRAE: Brasília, 2004, cap. 18.

${ }^{8}$ Nunes, L. C. C.; Galindo, A. B.; de Deus, A. S. O.; Rufino, D. A.; Randau, K. P.; Xavier, H. S.; Citó, A. M. G. L.; Neto, P. J. R. Variabilidade sazonal dos constituintes da própolis vermelha em bioatividade em Artermia salina. Revista Brasileira de Farmacognosia 2009, 19, 524. [CrossRef]

${ }^{9}$ Costa, A. S.; Machado, B. A. S.; Umsza-Guez, M. A.; Cirqueira, M. G.; Nunes, S. B.; Padilha, F. F. Levantamento dos estudos com a própolis produzida no estado da Bahia. Sitientibus série Ciências Biológicas 2013, 13, 1. [CrossRef]

${ }^{10}$ Lutosa, S. R.; Galindo, A. B.; Nunes, L. C. C.; Randau, K. P.; Rolim Neto, P. J. Própolis: atualizações sobre a química e a farmacologia. Revista Brasileira de Farmacognosia 2008, 18, 447. [CrossRef]

${ }^{11}$ Machado, B. A. S.; Cruz, L. S.; Nunes, S. B.; Umsza-Guez, M. A.; Padilha, F. F. Estudo prospectivo da própolis e tecnologias correlatas sob o enfoque em documentos de patentes depositados no Brasil. Revista Geintec 2012, 2, 221. [CrossRef]

12 World Health Organization/Food and Agriculture Organization. Codex Alimentarius Commission. Procedural Manual. 20th ed., Rome, 2011.

${ }^{13}$ Wang, L.-C.; Lin, Y.-L.; Liang, Y.-C.; Yang, Y.H.; Lee, J.-H.; Yu, H.-H.; Wu, W.-M.; Chiang, B.-L. The effect of caffeic acid phenethyl ester on the functions of human monocyte-derived dendritic cells. BMC Immunology 2009, 10, 1. [CrossRef] [PubMed]

${ }^{14}$ Lacerda, R. C. C.; Tiveron, A. P.; Alencar, S. $M$. Própolis e segurança alimentar. Segurança Alimentar e Nutricional 2011, 18, 99. [Link]

${ }^{15}$ Quintella, C. M.; Meira, M.; Kamei, A. G.; Tanajura, A. S.; da Silva, H. R. G. Prospecção Tecnológica como uma Ferramenta Aplicada em Ciência e Tecnologia para se Chegar à Inovação. Revista Virtual de Química 2011, 3, 406. [CrossRef]

${ }^{16}$ Hayacibara, M. F.; Koo, H.; Rosalen, P. L.; Duarte, S.; Franco, E. M.; Browen, W. H.; Ikegaki, M.; Cury, J. A. In vitro and in vivo effects of isolated fractions of Brazilian propolis on caries development. Journal of Ethnopharmacology 2005, 101, 110-115. [CrossRef] [PubMed]

${ }^{17}$ Franchise Help Page. Disponível em: $<$ https://www.franchisehelp.com/industryreports/green-industry-report/ $>$. Acesso em: 26 novembro 2014.

${ }^{18}$ Luis-Villaroya, A.; Espina, L.; GarcíaGonzalo, D.; Bayarri, S.; Pérez, C.; Pagán, R. Bioactive properties of a propolis-based dietary supplement and its use in combination with mild heat for apple juice preservation. International Journal of Food Microbiology 2015, 205, 90. [CrossRef] [PubMed]

${ }^{19}$ Duman, M.; Ozpolat, E. Effects of water extract of propolis on fresh shibuta (Barbus grypus) fillets during chilled storage. Food Chemistry 2015, 189, 80. [CrossRef] [PubMed] 
${ }^{20}$ Mahmoud, U. T.; Abdel-Rahman, M. A. M.; Darwish, M. H. A.; Applegate, T. J.; Cheng, H.$W$. Behavioral changes and feathering score in heat stressed broiler chickens fed diets containing different levels of propolis. Applied Animal Behaviour Science 2015, 166, 98. [CrossRef]
${ }^{21}$ Aguiar, S. C.; Cottica, S. M.; Boeing, J. S.; Samensari, R. B.; Santos, G. T.; Visentainer, J. V.; Zeoula, L. M. Effect of feeding phenolic compounds from propolis extracts to dairy cows on milk production, milk fatty acid composition, and the antioxidant capacity of milk. Animal Feed Science and Technology 2014, 193, 148. [CrossRef] 